\title{
Prosecutors' Habituation of Emotion Management in Swedish Courts
}

\author{
Åsa Wettergren (10) and Stina Bergman Blix
}

\begin{abstract}
The article examines the professional emotion management underlying prosecutors' work in court. Building on interviews and observations of forty-one prosecutors at five offices in Sweden, and drawing on sociological theories of emotion habituation, we analyze the emotion management necessary to perform frontstage (in court) professionalism as a prosecutor. We divide our analysis into three key dimensions of habituation: the feeling rules of confidence and mastering anxiety associated with an independent performance; the feeling rules of emotional distance and a balanced display associated with performing the objective party; and the playful and strategic improvisation of feeling rules associated with relaxed emotional presence. The routinization of feeling rules and the gradual backgrounding of related emotion management leads to habituation. Our findings enhance understanding of emotion management skills as part of tacit knowledge conveyed in the legal professions where emotion-talk and emotional reflexivity are little acknowledged. The article also contributes to the largely US-dominated previous research by adding a civil law perspective on prosecutorial emotion management.
\end{abstract}

\section{INTRODUCTION}

A tenacious "regime of judicial dispassion" (Maroney 2011) permeates the legal professions, relying on modern beliefs that reason and emotion are opposites and that unemotional reason is "a core requirement of the rule of law, a key to moving beyond the perceived irrationality and partiality of our collective past" (Maroney 2011b, 633). In contrast, past decades have seen a growing body of literature pointing out the necessity and usefulness of emotions in legal professional work (see for instance Lange 2002; Roach Anleu and Mack 2005; Maroney 2011b; Bandes and Blumenthal 2012; Maroney and Gross 2014). Legal professionals engage in emotion management, whether adapting their own emotional displays to the regime of judicial dispassion or maneuvering the emotions of others to achieve the work goals of the specific roles as judge, prosecutor (see for instance Bergman Blix and Wettergren 2018), and defense lawyer (see for instance Flower 2020). As this research shows, the performance of "unemotional

Åsa Wettergren (asa.wettergren@socav.gu.se) is Professor at the Department of Sociology and Work Science, University of Gothenburg, Sweden.

Stina Bergman Blix (stina.bergmanblix@soc.uu.se) is Associate Professor at the Department of Sociology, Uppsala University, Sweden.

The authors contributed equally to this work. We would like to thank Satu Heikkinen, Markus Arvidsson, and two anonymous reviewers for helpful feedback and suggestions. This project was made possible thanks to the Swedish Research Council (VR 2011-1553, VR 2016-01218) and the European Research Council (ERC) under the European Union's Horizon 2020 research and innovation program (757625, JUSTEMOTIONS). 
professionalism" requires extraordinary inter- and intra-professional emotional sensitivity (Barbalet 1998). However, the persistent idea that "professional means unemotional" (Goodrum and Stafford 2003, 188) hampers emotional reflexivity (Burkitt 2012) at work and thereby the assessment of the quality of emotion management and of the information brought by emotion (see Morton 2010). Learning the required emotion management conducive to one's profession becomes part of the tacit knowledge conveyed by work experience, and dependent on the individual capacity to master a "feel for the game" (see, for example, Goodrum and Stanford 2003).

The purpose of this article is twofold: to illuminate the crucial professional emotion management underlying prosecutors' work in court; and to analyze how prosecutors, through interaction with colleagues and laypeople, habituate the tacit feeling rules governing their professional emotion management. The limited previous research on prosecutors' emotion management mainly relates to how their work influences victims' emotions (Bandes 2006; Goodrum 2013) and to how prosecutors suffer and manage strong emotions evoked by tragic life stories encountered in their work (Goodrum and Stafford 2003; Leiterdorf-Shkedy and Gal 2019). In this article we focus on three key dimensions through which prosecutors learn to master frontstage (in court) professional performance and how this is linked to their habituation of core feeling rules. We focus on prosecutors' performance in court because the public representation of their work is where habituated emotion management skills manifest most clearly; in court prosecutors are on their own and must adapt to unexpected situations, simultaneously handling both their own and others' emotions.

Our findings enhance understanding of learning and mastering emotions as part of the tacit knowledge conveyed in professions where emotion-talk and emotional reflexivity are still considered alien to the work routine. We specifically focus on the understudied area of how prosecutors acquire the skills to master their own and others' emotions in court interactions. By using Sweden as a case study, our study also contributes to the US-dominated previous research by adding a civil law perspective on prosecutorial emotion management.

\section{AN EMOTION-SOCIOLOGICAL THEORETICAL FRAMEWORK}

Our theoretical framework builds on the sociology of emotions, in particular from Arlie Hochschild (for example 1983) and Jack Barbalet (for example 1998). In previous work, we have developed and adapted these perspectives to an emotion-sociological framework for analyzing emotions in the legal field (Bergman Blix and Wettergren 2016, 2018; Wettergren 2019; Bergman Blix 2021). Given that our purpose in this article is to analyze key dimensions of habituating prosecutorial emotions, we focus this theoretical section on explaining our overarching theoretical construct, the emotivecognitive judicial frame, and some of the empirically grounded concepts used in our analysis.

We rely on Thoit's sociological definition of emotion as comprising cognitive assessment, bodily sensations, "free or inhibited" expression, and a cultural label naming the emotion (Thoits 1989, 318). We thereby consider an emotion as a construction building on both social and socially adaptive biological components (cf. Rosenwein 
2010). We draw on Hochschild's (1983) classical concepts of feeling rules, denoting tacit norms about appropriate emotions and how emotions should be felt and displayed, and emotion management, denoting the physical and cognitive adaptation to feeling rules. Emotion management is analytically divided into deep acting, meaning that one adapts emotion by working on how one actually feels (e.g., through cognitive reframing, see Hochschild 1983), changing the emotion from the inside out, and surface acting, meaning that an emotion is displayed but (at least initially) not sincerely felt.

\section{The Emotive-Cognitive Judicial Frame}

Our analysis focuses on the feeling rules of prosecutors. These feeling rules can be seen as part of the emotive-cognitive judicial frame, which we suggest embraces all legal professions (see Wettergren and Bergman Blix 2016; Bergman Blix and Wettergren 2018). Frame is a contextual concept that denotes a taken-for-granted understanding of what is going on; frames organize and structure our experience of a situation and the norms for appropriate actions. The emotive-cognitive judicial frame is a concept we coined to highlight professional emotions, bridging emotional and cognitive behavioral norms of legal professional work (Wettergren and Bergman Blix 2016). People move between multiple frames in their everyday life, but some of these frames carry more weight: "the primary frameworks of a particular social group constitute a central element of its culture" (Goffman 1974, 27). The emotive-cognitive judicial frame is such a primary framework within the overarching emotional regime of judicial dispassion (Maroney 2011b) governing Western legal institutions. The modern discourse on emotions informing the regime of judicial dispassion-for instance that emotions are disruptive of reason, shaping legal professional practice to silence emotions (see Barbalet 1998) - is essential to the feeling rules in the emotive-cognitive judicial frame of courts and prosecution offices. The emotive-cognitive judicial frame thus carries, on the one hand, the overarching principle that legal work can and should be devoid of emotion, because the rule of law and the judicial system is constructed as objective, instrumental, and autonomous (Lange 2002; Maroney 2011a). On the other hand, the emotivecognitive judicial frame allows us to see how this principle, to perform legal work as if emotions were insignificant, is itself guided by emotion and requires skilled emotion management.

Using an interactionist emotion-sociological lens (Hochschild 1990), we emphasize that the emotive-cognitive judicial frame embeds feeling rules about appropriate professional emotions that are continuously reproduced and negotiated in situated professional interactions. Professional emotion management is simultaneously an individual task and an interactive, largely nonverbal, collective achievement. Consequently, situated emotion management is performed in multiple directions, inherently tying both self and others to the feeling rules as these are being made significant in a given interaction (Collins 1988).

Examples of this multidirectional emotion management can be when prosecutors juggle professional feeling rules, managing their own emotions in order to steer others' (professional as well as laypeople) emotional and cognitive judgment and impression of their performance as prosecutors (Goffman 1959). For instance, prosecutors may surface 
act confidence when they strive to perform the feeling rule that prosecutors should feel confident in their case, in spite of - and hiding - their actual feelings of nervousness and uncertainty. Or prosecutors may in fact feel confident but display a poker face-in our analysis a professional surface acting display_of uncertainty and confusion in order to trick a defendant to become less defensive during interrogation. In the first case, surface acting hides feelings of uncertainty that might disqualify one's professional appearance in the eyes of others. In the second case, surface acting is strategic emotion management inherent to confident professional performance.

Professional emotion management is in itself guided by emotions. Feelings of shame denote a large variety of emotions that signal a "threat to the social bond" (Scheff 1990; Scheff 2009), that is, feelings of being deemed unworthy of the esteem of the professional in-group (Kemper 2011). Feelings of shame range from light feelings of unease or embarrassment to, more rarely, mortification and self-remorse, and they spur desire to amend the damage (see Scheff 1990) or defend the self. Prosecutors we interviewed explicitly reflected on feelings of professional shame and associated them with breaking the norms of the emotive-cognitive judicial frame (Bergman Blix and Wettergren 2018). In contrast to shame, feelings of professional pride emerge in response to receiving esteem from the professional in-group, doing what is right and good according to the norms of the emotive-cognitive judicial frame (see Elias and Scotson 1994; Collins 2004). Feelings of pride encompass emotions like comfort/ease and are linked to self-confidence, or what we have called relaxed emotional presence in the analysis. In sum, feelings of professional shame and pride (or even anticipating such feelings) orient attention to the feeling rules and behavioral norms of the emotivecognitive frame shaping professional performance. Thus, even if the frame belongs to the unspoken knowledge of how to be a good prosecutor, "shaming" and "priding" makes it concrete and embodied through feeling (Collins 1988).

\section{Background Emotions and Habituation}

Our approach to professional emotions and emotion management is indebted to Barbalet's (1998) theory of emotion as involved in all types of action; suggesting that emotion and cognition, feeling and thinking, are intertwined and mutually conducive phenomena. In other words, rational action is emotional (see also Damasio 2000; Feldman Barrett 2017). To grasp how this works, Barbalet suggests the concepts of background and foreground emotions. Background emotions refer to often calm and quiet emotions that the emoting subject generally does not register as emotions because they are conducive to rational action by motivating, sustaining, and orienting focus (Barbalet 2011). Background emotions of confidence and certainty in their cases sustain prosecutors' professional performance and even allow them to improvise and play with this performance, as in the abovementioned example of surface acting uncertainty when cross-examining a defendant.

Foreground emotions, on the other hand, are relatively strongly expressed and/or experienced and thus registered both by the emoting subject and by others (if not successfully managed by deep or surface acting). They include emotions disruptive of the professional focus, such as becoming too attached to a particular case, too nervous to 
perform in court, too angry at the defense, or too stressed by work overload. Foreground emotions may be seen as weak and unprofessional by colleagues, and they tend to be registered by the emoting subject as "disturbing," requiring conscious management to return to a cool and professional state of mind. Foreground emotions denote what legal professionals spontaneously think of as "being emotional." Whereas background emotions orient and inform professional goals without calling attention to themselves as emotions, foreground emotions enter the emoting subject's consciousness and disturb their professional focus (Barbalet 2011).

Advancing the concept of background emotions, we suggest that emotion management also appears in a backgrounded version (Wettergren 2019, 30), which means that emotion management can take place below the emoting subject's consciousness. This is the result of a learning process through which, in the case of the prosecutors, socialization of the emotive-cognitive judicial frame backgrounds its feeling rules and corresponding management. We call this habituation (Bergman Blix 2015b), which in our theoretical framework denotes how repetition, experience, and routine make frames and their feeling rules embodied and mostly nonreflexive practice. Habituation backgrounds professional emotions along with the required emotion management; as work routine settles, the enactment of the norms of the emotive-cognitive judicial frame becomes an embodied and habituated part of one's professional identity (see Scheer 2012).

\section{EMOTION MANAGEMENT IN THE LEGAL PROFESSIONS}

Scholarly interest in the role of emotions in various legal professions such as judges (Roach Anleu and Mack 2005; Maroney 2011a; Scarduzio 2011), prosecutors (Goodrum and Stafford 2003; Bandes 2006; Wettergren and Bergman Blix 2016; Leiterdorf-Shkedy and Gal 2019), defense lawyers (Harris 2002; Austin and Durr 2016; Flower 2018), and paralegals (Pierce 1999; Lively 2002) demonstrates that these professions need to manage their own emotions to display impartiality, fairness, or loyalty before the public; manage others' emotions to run efficient investigations, examinations, and procedures (Roach Anleu and Mack 2005; Flower 2018); and manage each other's emotions to cope with the strains of their work (Lively 2000).

The norm of judicial dispassion requires distancing of one's own feelings (Lively 2002) and tends to make emotional displays subtle so as not to break with the ideal of dispassion (Maroney 2011b; Wettergren and Bergman Blix 2016). Yet, legal professionals in high-status positions, in particular judges, may deviate from these feeling rules and strategically use humor (Milner Davis and Roach Anleu 2018) or displays of anger, frustration, and rudeness as power devices to speed up court procedure, relieve tension, and govern clients' behavior (Mack and Roach Anleu 2010; Scarduzio 2011).

For prosecutors, upholding objectivity requires conflicting emotional balancing acts. Studies show that prosecutors continually negotiate and do objectivity in situated legal practice (Rogers and Erez 1999; Jacobsson 2008), an endeavor that involves multidirectional emotion management (Bergman Blix and Wettergren 2019). In adversarial systems, prosecutors' need to perform objectivity can clash with their role as advocates. A felt affiliation with the victim can impede empathy with 
the defendant and make prosecutors prone to prioritize their narrower function as advocates over their abstract function of protecting justice (Bandes 2006). In two American studies, prosecutors stressed their role as neutral public servants but often also connected this role with "being at war on crime" (Felkenes 1975, 107), even aiming for "total annihilation" of the defense (Smith 2000, 375). Smith argues that prosecutors may adopt a narrow interpretation of the rule of law by fostering a stereotypical understanding of people's (in particular defendants') motivations and aims. Prosecutors have a propensity for "smugness"; they do not have to consider the "shades of grey" that a defense lawyer representing a human client needs to take into account (2012, 949). However, another American study on prosecutors' tendency to leave their jobs found that the emotional balancing act of performing as objective was perceived as stressful ( $\mathrm{Na}$, Choo, and Klingfuss 2018).

As discussed in the theory section, legal professionals do not only manage their own emotions to perform professionally. In order to gain relevant information for their decisions and to gain public trust for the legal process, legal professionals need to attend to the emotions of accused, victims, and witnesses (Goodrum and Stafford 2003; Roach Anleu and Mack 2005; Moorhead 2007). Empathy, the capacity to imagine being the other and what the other might feel and do, is crucial since the legitimacy of the law presumes that both sides are heard, requiring judges and prosecutors to fathom multiple perspectives (Henderson 1987). Goodrum (2013) argues that prosecutors' emapthic approach to victims positively influences the legitimacy of the legal system by increasing victims' satisfaction. However, empathy also has to be restrained to uphold professional focus. Goodrum and Stafford $(2003,188)$ found that US prosecutors used their status and the victim counsels as shields against emotionally upset victims. In examinations and cross-examinations prosecutors may engage in strategic emotion management, expressing frustration, sarcasm, or sympathy to impel victims, defendants, or witnesses to express for example sadness or anger (Brannigan and Lynch 1987; Wettergren and Bergman Blix 2016; Leiterdorf-Shkedy and Gal 2019).

In spite of the skilled emotion management required for professional legal performance, emotional training to develop these skills is scarce in law schools in both Sweden and the United States (Flower 2014; Austin and Durr 2016). Professional emotion management belongs to the tacitly communicated and acquired skills of legal professions, where novice prosecutors "learn by observing and emulating colleagues and through their own mistakes" (Seymore and Sandiford 2005). In Seymour and Sandiford's study lack of training is explained by lack of resources in service organizations, but our previous research suggests that emotional training is also discredited by a widespread reluctance to acknowledge emotion work in resourceful organizations like the courts and prosecution offices (Flower 2014; Bergman Blix and Wettergren 2018).

In a study on paralegals, Lively (2000) coined the concept of "reciprocal emotion management" to capture the mutual emotion management between similar (subordinate) others within a law firm. Francis (2006) analyzed reciprocal emotion management and unstable professional identity for female legal executives and found that legal executives did not form similar alliances. Instead, they prioritized good relationships with their subordinates, based on shared gendered experience of contested status. In our previous work (Wettergren and Bergman Blix 2016; Bergman Blix and Wettergren 2018), we found that prosecutors' identity as high-status independent legal professionals is 
unstable because they depend on multiple others to do their work, including professional groups and laypeople. Prosecutors thus experience bounded independence because their efficacy relies on managing emotions to bolster smooth relations with these multiple others who deliver important material for the prosecutors' case or provide them space and opportunity to elaborate their case in court.

In sum, a growing field of research on the role of emotion and emotion management in the legal professions has focused particularly on empathy; on discrete emotions, such as anger or sadness; and on professional emotional strategies, such as humor. There is scarce previous research on how these tacit skills of professional emotion management become acquired. This is particularly interesting because although emotional training is virtually nonexistent, emotion management is arguably at the heart of legal professional performance. The analysis presented in this article addresses this knowledge gap by analyzing the case of Swedish prosecutors.

\section{METHOD}

This article draws on two large projects (running 2012-2019) financed by the Swedish Research Council, in which we studied judges' and prosecutors' professional emotions, exploring how emotions are active and acted upon in and around court hearings (VR 2011-1553), and the emotive-cognitive construction of objectivity in judicial decision making (VR 2016-01218). These projects engaged five prosecution officesthree in small or medium towns, two in larger cities - and used a combination of ethnographic methods: shadowing, observations, and interviews.

Shadowing involves following a person for a period to see their work life from the inside, and it includes both interviews and observations (Czarniawska 2011). We shadowed prosecutors to study preparation of cases, court work, and shifts between in- and out-of-court performance. This included nonparticipant observations of the prosecutor during trials and participant observations with the prosecutor during "in-between" situations (office work, breaks, walking to/from court). In observations of trials we focused on context-bound emotional communication, such as body language, mimics, gestures, glances, voice, and word choices. After hearings we engaged with prosecutors' reflections. Each shadowed person was formally interviewed following a semistructured interview guide, inquiring into emotional processes and professional role performance, when and which emotions are appropriate, relations to colleagues and laypeople, and inter-professional tacit signals in court. We also conducted audio-recorded follow-up interviews with shadowed participants after observed trials.

The method of shadowing enabled us to uncover professional background emotions. We continuously engaged prosecutors in conversations and small talk about situations observed. Ongoing conversation was then combined with the follow-up interviews, for which we used our observation notes to help participants recall courtroom situations. Thus, using concrete and temporally close events, these techniques invited reflection on background emotions such as calm and tempered feelings of surprise, irritation, concern, interest, boredom, embarrassment, sternness, etc. As these background emotions are inherent in the daily flow of professional business as usual, they were not likely to be recalled in the larger semistructured interviews. If they were, 
participants were at pains trying to remember concrete examples. The method of shadowing as combined with follow-up interviews thus allowed retracing background emotional processes that orient and sustain professional performance.

To focus our attention on the fluctuation of emotional intensity during observations, we employed "emotional participation," a method in which our own emotions were used as tracking devices to generate preliminary interpretations of the situations observed (Wettergren 2015; Bergman Blix 2015a). Although these preliminary interpretations were not necessarily accurate, we could still use them to guide the selection of situations asked about in the follow-ups.

\section{Data and Analysis}

Forty-one prosecutors were interviewed and shadowed from three days to several weeks. The selection of participants accounted for gender, age, and length of work experience. In total, we made sixty-two audio-recorded interviews with twenty-three women and eighteen men, between twenty-seven and sixty-eight years of age, with work experience ranging from two months to forty-plus years. The interviews ranged in time between thirty minutes (follow-ups) to two hours and fifteen minutes, averaging two hours. Around three hundred criminal hearings were observed. The data was anonymized and coded in a software program for qualitative data analysis, NVivo.

The analysis was abductive, combining empirical codes with theoretical sensitizing concepts (Alvesson and Sköldberg 2009). For instance, the theoretical concept of background emotions was brought to the empirical field and permeated the data collection and analysis in the sense that we deliberately focused on the barely visible displays of emotion as described above. We also adopted the notion of "professional emotions" to separate these from the private and personal realm that were not part of our study. In this context, it should be explained that professional emotions can also be foreground emotions, although in the Swedish courts, foreground emotions are also very subtly expressed. For prosecutors, this can be, for instance, intensive excitement when a cross-examination breaks through what had previously been considered a deadlock. Our analysis produced empirically based concepts such as elaborate insensitivity, poker face, and relaxed emotional presence (we further discuss these concepts below).

Our analysis is structured around three key dimensions: (1) Habituating independent performance: mastering anxiety and displaying confidence; (2) Performing the objective party; and (3) Relaxed emotional presence. The dimensions should be understood as overlapping and variously accentuated at different stages in the course of prosecutors' work life experience. To some extent, the second dimension presumes mastery of the first, and the third dimension presumes mastery of the first and the second dimensions. To give an example: unexperienced prosecutors adopt a stubborn sense of elaborate insensitivity to protect themselves against what they perceive as the defense lawyers' attempt to undermine their case in court, or the presiding judge's presumed irritability. This is a recurrent strategy we found among different prosecutors and commonly among the young and inexperienced. We named this pattern "elaborate insensitivity" and refer to it as a component in the key dimension primarily present in the early process of becoming a confident public prosecutor. Although in the real world the 
patterns we have clustered into key dimensions are more mixed, intertwined, and messy, organizing them in this way enhances the analytical clarity of our argument about gradual habituation.

The excerpts in the analysis are followed by a pseudonym, position (assistant/ public/chief prosecutor), and age of participant rounded off to $+/$ - five years. Age is used here as an indicator of work experience. ${ }^{1}$

\section{Note on Prosecutors in Sweden}

The Swedish judicial system uses adversarial trials but the investigation and the overall judicial organization pertain to the civil law system and an inquisitorial tradition. Swedish prosecutors lead preliminary investigations, decide on coercive measures, file indictments (or close down cases), and represent the state in court hearings. Following the civil law system, the preliminary investigation is inquisitorial, requiring the prosecutor to pursue an impartial investigation, but the trial is adversarial. This requires the prosecutor to be both partial and objective in court (Zila 2006).

To become a prosecutor, the most common next step after law school is applying to serve as a legal clerk in one of the courts. The legal clerk is a training position that involves courses, preparing cases, taking notes in court, and writing draft judgments. After two years, a clerk can apply to become a prosecutor trainee. After nine months of probationary employment, trainees apply to become prosecutors. They advance to the role of public prosecutor after a two-year assistantship. All but two courses clerks and trainees take are focused on legal issues: a course on rhetoric and another on selfpresentation in and out of court. Emotion or emotion management are not mentioned in training.

\section{HABITUATING INDEPENDENT PERFORMANCE: CONFIDENCE AND MASTERING ANXIETY}

The first key dimension in our analysis links to the feeling rules of confidence and mastering anxiety necessary to habituate an independent performance. To carry and publicly perform one's role with confidence signifies a competent prosecutor. Confidence signals that the case has been thoroughly and objectively investigated, leaving no loose threads and no doubt that all the evidence points to the accused. Adaptation to these feeling rules for new prosecutors requires conscious and focused management of foreground anxiety. The feeling rules of confidence and mastering anxiety are conversely manifested in the ease by which experienced prosecutors report anxiety in passing, subsumed by the confidence and certainty in a proper investigation. As Prosecutor Bror $(65+)$ explained:

1. We have chosen to use age instead of years of experience since it turned out to be the most reliable measure. Years of experience raised issues about when to start counting relevant experience for the professional work. Prosecutors can have worked in different positions in court or as lawyers before entering the prosecutorial profession. 
Leading the preliminary investigations is the most interesting part, because you get to be creative and to take this raw material to polish it somehow so it becomes a diamond that you present to the court .... Leading preliminary investigations also entails a lower level of anxiety than being in court, but I think it would be tedious to only do that. I mean it is also fun to be in court, depending on the type of case. Grey trials [minor offenses] are relaxing in a way and it takes you away from, you sit there in court and simply cannot be reached on the telephone ...

In this quote, Bror seems to prefer leading preliminary investigations, describing calm, supportive background emotions of interest, pride, and satisfaction, implicating the flow of good collaboration with efficient police detectives. In contrast, going to court is tied to anxiety, but Bror's way of talking reveals that anxiety too is a calm background emotion, while emphasizing fun and break with tediousness as supportive emotions associated with trials. He even uses the courtroom as a space to relax, indicating his successful background management of court anxiety. The metaphor of the polished diamond points to how prosecutors, when they follow a case from investigation to court, can be confident and in control of their case.

Court anxiety as a lingering emotion even for experienced prosecutors derives from the fact that during trials prosecutors are the default target of critique concerning shortcomings of the preliminary investigation, the evidence, and the presentation and legal encoding of the case. They thus become objects of both background and foreground irritation (e.g., by the judge), scorn (e.g., by the defense), and resentment (e.g., by the accused). In our data, new prosecutors felt particularly concerned about coping with foreground disruptive emotions of uncertainty, anxiety, anticipated shame, and frustration. They above all worried about the presiding judges: whether they would be indulgent or impatient toward prosecutors in training (Wettergren and Bergman Blix 2016). As we will demonstrate, the difference between experienced and new prosecutors is that the former have backgrounded the management of anxiety and thereby habituated confident performance, while new prosecutors struggle with foreground anxiety that they consciously need to hide by surface acting confidence (see Flam 2005).

As Bror's reflections show, a common way that prosecutors deep act confidence before going to court is to be well prepared regarding the case, drawing confidence from the cognitive framing that they "know the case." Experienced prosecutors thoroughly prepare larger cases in which they themselves have been leading the preliminary investigation. In minor cases, routinely investigated by colleagues, they lean on experience to improvise performance in court as the trial goes, thus demonstrating relaxed emotional presence. New prosecutors, by contrast, spend time preparing even minor cases to achieve this deep-acted confidence, negligent of the fact that to know the case is not as easy as is taught in law school. ${ }^{2}$ Prosecutors need to anticipate the possible

2. Large and severe cases are usually "locked" to a single prosecutor, who is responsible for the investigation, indictment, and court proceedings. New prosecutors usually go to court with minor cases that other prosecutors have investigated and indicted. This, and the fact that prosecutors are given relatively little preparation time for minor cases, means that there are limited possibilities to "know" the case (but new prosecutors may spend their free time for extensive preparations). The prosecutors taking a minor case to court are therefore less in control of the case in terms of "knowing" it than they are when they are backed 
viewpoints of various judges as they plan and prepare their case, and be sensitive to the specific presiding judges' signals and adapt accordingly in court. Even experienced prosecutors like Chief Prosecutor Philip (40+) consider this a predicament with unknown judges:

Some judges allow more questions and more deviations both from me and from the witnesses, while others in principle don't want any long examinations .... When you know a judge you know if they will allow more leeway or if they are grumpy, but if it's a new judge, you don't dare to go in and just go for it.

Adherence to individual judges' style of presiding is part of the prosecutors' emotion management in the courtroom, and it encompasses simultaneously dealing with the prosecutor's own emotions and the judge's. A satisfied judge is conducive to a prosecutor's goal to act independently in court, claiming space to confidently present the case. Mistakes in navigating this emotive-cognitive landscape in court can deprive prosecutors of the control of the case and the trial procedure.

\section{Protecting Confidence with Elaborate Insensitivity}

Being sensitive to the judge is only one aspect of a successful court performance. An efficient prosecutor needs to master examinations. Examination techniques are not part of mandatory education for prosecutors, so the strategic emotion management beneficial to asking questions in an efficient way is learned by doing (cf. Seymour and Sandiford 2005). It is common for new prosecutors to prepare a battery of detailed questions based on police interrogation protocols, leaving them at risk of losing control if the examined change their story. When this happens, lack of experience and foreground management of anxiety makes many new prosecutors react slowly or repetitively, instead of quickly adapting and improvising. The following excerpt is from observation notes of a court examination of an accused who had confessed in the police interrogations, but now tells a different story. Assistant Prosecutor Magnus (30+) gets stuck trying to make the accused repeat statements in the police interrogation protocol, while the judge gets increasingly frustrated:

The prosecutor seems utterly unconcerned by the growing impatience in the courtroom: instead of speeding up, he rather slows down. He immerses himself in his papers, leafs through them slowly, and puts the same questions over and over again to the defendant, who protests that he has already answered. The judge intervenes: "We've already talked about that before, so let's move on." Finally the judge says: "The court has understood this by now." The prosecutor insists that he himself does not understand. (Observation, unlawful threat, Assistant Prosecutor Magnus, 30+)

by their own investigations in "locked" cases. That said, experienced prosecutors who master the dimension of what we call "relaxed emotional presence" manage the uncertainty of these minor cases with ease and improvisation (see for instance Prosecutor Faida in the Relaxed Emotional Presence section below). 
Magnus tries to win time by dragging out the examination, repeating the questions, ignoring the judge by pretending not to sense the growing irritation, and verbally defying the judge by insisting that he has not understood. He sacrifices attentiveness to the judge's signals to claim space and protect his surface-acted confidence. We call this insensitivity to the judge's signals and growing irritation elaborate insensitivity. It is a commonly used strategy among new prosecutors to ward off shaming (disregarding the regard of others, see Scheff 1990) in order to allow time to think about how to proceed. Putting on a poker face of confidence, elaborate insensitivity hides nervousness or growing panic over loss of control, at the risk that the judge interferes and reduces the prosecutor's action space (see Mack and Roach Anleu 2010).

We also see in the excerpt that the accused resents Assistant Prosecutor Magnus's repetitiveness. The Swedish legal system generally advocates an empathetic approach toward defendants to enhance their acceptance of being found guilty (cf. Goodrum 2013). In our data, new prosecutors sometimes behaved as if confidence in the case (pointing out the defendant as guilty) motivated moral righteousness, resulting in a condescending attitude toward defendants (cf. Smith 2000). This is arguably a side effect of their conscious effort to master anxiety and display confidence. Elaborate insensitivity may result in a "shame-anger spiral" (Scheff 1990), where shame triggers defiance, triggering more shame and more defiance.

When we shadowed Assistant Prosecutor Katla (30+) on a case that she was forced to take over from a much more experienced public prosecutor on sick leave, Katla talked openly with the researcher about her foreground anxiety; she discussed her shame about investigative measures she had failed to take and expressed doubt regarding the suspect's guilt. To cover the gaps in her investigation, during the trial she focused on her own confident appearance and tried to push the defendant to confess. Below is a description of her unusually long cross-examination of the defendant, who was charged with an aggravated drug crime and drunk driving, in which we see a shame-anger spiral unfolding (shaming instances and defenses marked in bold):

The prosecutor has an incredulous face, making her words sound ironic: "Ok! So your intention was to make a complaint about the cocaine?" She purses her lips. The defendant's answer gets even more tangled up, his entire body posture collapses and his head falls down. The prosecutor changes topic and asks about the car ride. The defendant answers with a tired, resigned voice. The prosecutor looks accusing, knitting her brows, her chin resting lightly on the top of her fingers. Prosecutor: "And what's the name of this friend?" Defendant: "What can I say, the police know ... " Prosecutor: "Really?! I can't see it ..." She scrolls the protocol in her computer. The defense lawyer interrupts, verifying that the name is in the protocol. Prosecutor: "Yes, but not the family name, right? [turning to the defendant] What's his family name then?" The defense lawyer to the prosecutor, sounding mildly reproaching: "The prosecutor knows it is a sensitive topic." The prosecutor straightens her back and looks away. "Yes, I understand that, but one can chose to answer or not answer" she replies curtly. 
In this case, the judge did not intervene but the defense lawyer (a very experienced elderly man reputed to be both wise and kind) expressed clear signs of disapproval, intervening twice to correct Katla's method of interrogation. Katla's reaction to this as a shaming-event is displayed both in her verbal defenses ("Yes, but ... ." and "Yes, I understand that but ...") and in her stiffening body posture, turning her face away, and curt reply. As with Assistant Prosecutor Magnus, we see how Katla's defense against shame includes the display of elaborate insensitivity, insisting on and repeating apparently pointless questions. Protecting confidence is done at the expense of empathy with the defendant.

With an active judge, the shame-anger spiral can ruin the prosecutor's control altogether. Prosecutor Trainee Agnes (30+) reflected a lot on the intersection of gender and age in the legal professions (cf. Pierce 1999) and on deflecting elder male colleagues' attempts to lower her confidence. She describes her interaction with a particular judge:

There is this judge, he starts huffing and puffing quite early, so I think: "No, you'll have to try to throw me off balance, I'm not changing my planned course of action." Sometimes I can get stressed out about things like that, but sometimes I just think to myself, "I don't give a damn." If he wants to interfere, he'll have to actually tell me "This has been clarified already," or something.

Elaborate insensitivity in this quote is fired by righteous anger ("I don't give a damn") originating in a gender-conscious standpoint. The outcome, if the judge removes her initiative, is nevertheless a shameful professional failure, making Agnes's resistance a double-edged sword.

\section{Mastering Anxiety by Team Scaffolding}

New prosecutors running into changed circumstances and rising levels of anxiety can get help from experienced prosecutors, "scaffolding" their display of confidence by showing the technique of quick adaptive emotion management. By scaffolding we here refer to the implicit and explicit collective collegial support in building up confidence (cf. McGeer 2004).

On the one hand, feeling rules of confidence and mastering anxiety must be displayed before they are habituated for new prosecutors to appear as "the right type of person" for the job (cf. Goodrum and Stafford 2003). This means that prosecutors are inherently expected to be "tough" as persons. On the other hand, our study shows that this expectation tends to produce a strong sense of team spirit and solidarity at the prosecution office, indicating collective understanding of the emotional costs involved. The team spirit includes feeling rules demonstrating prosecutors' independence as bounded not only inter-professionally but also intra-professionally; their display of confidence in court is collegially supported (Bergman Blix and Wettergren 2018). One such intra-professional feeling rule is collegial generosity: sharing professional knowledge, experience, and expertise as a means of reducing stress. The feeling rule of generosity is a type of reciprocal emotion management (Lively 2000), which in this intra-professional context relies on an exchange of mutual sympathy for the difficulties prosecutors 
regularly run into and a readiness to offer and accept sympathy for professional mishaps, failures, frustrations. As argued by Clark (1997), mutual sympathy exchange builds equality, trust, intimacy-it is a key component of the team spirit. Prosecutor Wenche $(35+)$ describes this:

This job is too tough for the colleagues to be tough on each other. We are quite a tight team ... If you need an outlet, if you are frustrated about the police, the lawyers, the court, you have to be able to ventilate that, and the climate here is so open that it is easy to do that.

In court, as we saw in the example of Assistant Prosecutor Magnus, prosecutors sit alone and need to manage and situationally adapt to new situations in the courtroom on their own, and they may get stuck, as Magnus did. If instead there is a chance to get a break, they can call a colleague for advice, or ask a random colleague in the prosecutors' room at the courthouse. During shadowing, we observed several instances of knowledge and sympathy exchange in backstage settings at the courthouse or the prosecution offices. Both senior and junior prosecutors draw on the feeling rule of generosity, but it is obviously invaluable to new prosecutors.

In one shadowed case, Assistant Prosecutor Anneli (30+) was sitting in the prosecutor's room in the courthouse, preparing her next trial-a theft case. Reading the police interrogation protocol, she discovered that the suspect might in fact not have passed the pay desk before being arrested. This meant he was intercepted before he had stolen anything and thus he was innocent of theft. Anneli started fidgeting and looked repeatedly at her watch; clearly alarmed as the trial was about to begin soon. Reaching out to the experienced Prosecutor Anna (45+), who happened to be in the same room, the situation developed as follows:

Anna wants to see the charges, reads through them quickly and says with a calm voice and expressed ease: "I would've put it like this" ... She dictates to Anneli who writes down what she says, word by word: "The alternative charge is 'attempt to steal' ... " Anna says: "But I wouldn't declare that openly right away. You'd rather wait until after you've examined him.”

During the trial, a witness testifies that the accused did not pass the pay desk before he was arrested. When the examination of the witness is over, Anneli turns to the judge and states: "On account of the last witness statement, I have an alternative charge to present ..." She then repeats verbatim what Anna had told her, displaying clear and calm confidence. (Observation, theft, Assistant Prosecutor Anneli, 30+)

In the context of shadowing Anneli for a full day of trials, her sudden fidgeting and questions about this matter revealed signs of panicking, though she did not tell Anna, her senior, that she felt this way since it might have broken the rule of mastering anxiety. Yet, asking for advice was in line with the feeling rules of generosity and sympathy: it revealed Anneli's lack of experience but being in a situation of inexperience is something that most prosecutors remember. Equipped with an alternative charge, but 
also with the confident strategy to hold back on it until the primary charge was proven invalid, Anneli demonstrated ability to quickly and elegantly adapt the charges to the new information. When leaving the court after this final trial, Anneli's relief came through as she exclaimed: "Tonight I will eat chocolate!" This intention to reward herself indicated relief from the anxiety she had actually felt.

Experienced prosecutors are generally skilled at quick adaptive emotion management in court (Bergman Blix and Wettergren 2015), denoting this ability to confidently and swiftly adjust to changed information, situations, or behaviors of others in court (Roach Anleu and Mack 2021). In Anneli's case, we witnessed how this quick adaptive emotion management depended on and was supported by the feeling rule of intraprofessional generosity.

In this and the previous subsections we have analyzed aspects of the dimension "Habituating independence by mastering anxiety and displaying confidence." Anxiety associated with going to court tends to be foregrounded in inexperienced prosecutors, and the confidence is often surface acted as a poker-face display, rather than sincerely felt. Given the feeling rule of mastering anxiety and displaying confidence as a crucial sign of prosecutorial competence, we have seen how conscious emotion management is required to achieve both these ends. Prosecutors focus on protecting their confident performance by adopting the technique of elaborate insensitivity. Elaborate insensitivity inhibits attentiveness to the judge's signals, which prosecutors need to smoothly carry through with the trial and remain in control of the case presentation. Elaborate insensitivity may also affect the interaction with the defendant at the expense of an empathetic approach, an institutionally embraced feeling rule. This means that while elaborate insensitivity is an emotion management strategy to surface act confidence and keep foreground anxiety at bay, it may deprive the prosecutor of control and collegial esteem.

A complementary way of mastering anxiety and displaying confidence is to draw on the intra-professional feeling rules of generosity and sympathy constitutive of prosecutors' team spirit. The team spirit generally buffers the toughness of prosecutors' job and may come in handy to scaffold new prosecutors' confident performance. The feeling rule of intraprofessional generosity requires that junior prosecutors manage their anxiety in relation to senior prosecutors, not to appear too insecure or independent and thus unfit for the job.

Accumulated work experience, encountering multiple situations like those exemplified in this section, and gaining experience with larger court cases where confidence originates in leading the preliminary investigation, gradually leads to habituation of the feeling rules. Anxiety management becomes backgrounded and confidence is more often deep acted through knowledge of the case, or simply leaning on past achievements. As seen in the introduction of this section, due to the continuous need to adapt to unexpected situations, feelings of anxiety do not necessarily disappear with more experience but managing anxiety is no longer in conscious focus.

\section{PERFORMING THE OBJECTIVE PARTY}

The second key dimension in our analysis focuses on the performance of objectivity in court, a professional imperative that is linked to feeling rules of emotional distance 
and a balanced display. In our previous work (Wettergren and Bergman Blix 2016; Bergman Blix and Wettergren 2018, 2019) we have treated the topic of emotion management involved in "doing objectivity" in depth. In this section, our focus is limited to prosecutors' "performance of the objective party in court" as a crucial dimension in the habituation of professional prosecutorial emotion management.

Experienced prosecutors are familiar with most situations in court, shifting their attention from protecting confidence and mastering anxiety to cultivating their court persona and its poker-face strategies along with elaborated examination techniques. They also explore how to perform "the objective party" - the ability to switch on and off emotions of commitment to the case (partial) and commitment to the state (objective) (Weber 1998). Rather than fearing critique from the judge and the defense lawyer, the prosecutors consider themselves as having a part in the collaborative production of legal objectivity, requiring inter-professional exchange of emotional communication (subtle communication of concern for the lay parties through, for instance, exchanging gazes) and tacit signals (for instance articulations of legal phrases carrying specific meaning only to the legal professionals) (Bergman Blix and Wettergren 2019). The dimension of performing the objective party is reflected by Prosecutor Anna $(45+)$ below:

There can be many different emotions evoked inside me ... and I need to reflect on that and remember that objectivity is really important and indeed if the accused has no defense lawyer or if the defense lawyer overlooks something I must try to bring up absolutely everything that may speak to the accused's advantage. So yes, be objective and think about it, I mean, it is better if ten guilty persons walk than if one innocent person is convicted.

Prosecutors act as party in court but, as state representatives, they still need to be objective (cf. Bandes 2006; Jacobsson 2008). This paradoxical position requires prosecutors to develop capability for strategic, reflective emotion work, continuously monitoring whether the defense's story might call the charges into question-in effect heeding a possible shift from a partial to an objective emotive-cognitive goal orientation (for details of this see Bergman Blix and Wettergren 2019). This reflective emotivecognitive work is facilitated if prosecutors have habituated the performance of confidence in the case and backgrounded anxiety management. They also benefit from having acquired skills of quick adaptation-flexibility for the fluent situation in court, balancing independence and sensitivity toward the other legal professionals (notably the judge). The prosecutor may then turn from focusing on the role of the party, eager to prove their case, to presenting an articulate objective demeanor. In the excerpt below, Prosecutor Linda (35+) is examining a prosecution witness:

The prosecutor asks the witness to recount her memory of the event, but interrupts her soon thereafter, asking how close to the incident she was at the time. When the witness has finished her account, the prosecutor asks if it was dark and, when the witness answers in the affirmative, whether she really could see what was happening. At the end of the examination the prosecutor asks: "Is there anything in what you have told me that you 
feel uncertain about?" The witness answers: "No." During the examination, the prosecutor never smiles, and there is sometimes a tone of doubt in her voice. (Observation, infliction of damage, Prosecutor Linda, 35+)

In this trial, Linda employed the same skeptical style of examination for all witnesses, regardless of whether they were prosecution or defense witnesses. This neutral approach is a way of doing objectivity by demonstrating to the defendant and the victim that everyone is treated equally, drawing on empathetic imagination of how the examinations appear from their perspectives. Confidence in the case and familiarity with trial procedure and techniques also enable Linda to improvise questions to fit the live storytelling of witnesses. Skepticism and doubt serve the strategic purpose to forestall the defense by asking the defense critical questions and to win the trust of the judge by demonstrating that the prosecutor is confident in the strength of the case (cf. Goffman 1961).

Examination styles thus evolve from the rigid and confrontational approach we saw from new prosecutors to more neutral approaches as prosecutors become more confident. To achieve a neutral and empathetic examination style, prosecutors distance themselves from the defendant's resistance and provocation. Prosecutor Arne (35+) describes how this emotional distancing strategy relies on elaborate preparations before going to court (see note 2 above):

The defendant can tell me he was on the moon [when the crime was committed], it doesn't matter, because we've built this case so well it doesn't matter what he says. We have witnesses who describe what happened, we have technical evidence showing that he was at the crime scene, we have his phones showing who he talked to, we have his computer showing how he planned this.... If you do the preliminary investigation really well, you don't need to get into conflicts in court, and then I don't need to get all psyched up. (Prosecutor Arne, 35+)

In this quote Arne clearly ties neutrality (not getting "psyched up" when examining the defendant) to confidence in knowledge of the case.

Linda's and Arne's focus on objectivity enabled them to disassociate their professional conviction about the defendant's guilt from their display in court. Displaying of objectivity by a neutral examination style is the result of a focus shift, from mastering the role of a confident and independent party to mastering the role of an objective party. Objectivity display thus relies on habituated confidence display. The first dimension of building confidence and mastering anxiety demands a protective shield against displays of irritation (particularly by judges). The second dimension of displaying objectivity demands distancing of the prosecutors' own emotions of engagement in a case and those of prosecutorial witnesses to succeed in representing the (objective) state party (cf. Rogers and Erez 1999; Jacobsson 2008).

The focus on an objective performance thus emphasizes emotional balance and neutrality. The prosecutor strives to be equally interested or equally skeptical in all examinations, whether the account is favorable to the indictment or not. For more experienced prosecutors, this understanding of an objective performance often gives 
way to a more nuanced interpretation, separating the performance in every interaction from the overarching goal of reaching an objectively legitimate result.

\section{RELAXED EMOTIONAL PRESENCE}

The first two dimensions examined so far involve strategies to keep emotions at bay. In contrast, in the third key dimension emotional presence is in focus, signifying the ability to play with the feeling rules of the strict objective display demanded in court. As evidenced by Prosecutor Jakob (50+), emotional presence is crucial to being able to adapt to the ever-changing circumstances of court proceedings:

Flexibility, to be exact, right, the manuscript changes and I mean, you can go [to court] with your manuscript and then that does not fit at all because new situations emerge and I believe that's where experience matters, that is, your ability to adapt to the way the trial evolves. (Prosecutor Jakob, 50+)

Jakob articulates a habituated emotion management of performing the objective party along with familiarity with the court procedure. As seen earlier when Anneli received help from Anna to swiftly adapt her strategy, the third dimension of emotional presence is important for prosecutors at all levels of experience. However, experienced prosecutors, like Jakob, can focus on "situated adaptation"-emotive-cognitive assessments of what type of situated action and interaction is needed - when they meet the defendant, the victim, or the witnesses.

Experienced prosecutors develop a court persona and an examination style. This enables a presence where prosecutors remain sensitive to the flow of emotion in court, the shifting moods and atmospheres, and the emotional communication and tacit signals between legal professionals that promote smooth proceedings. In the following excerpt, Prosecutor Faida (40+) examined a young man who was locked in a youth care institution and accused of threatening to kill a social worker when she delivered the news that he would not be released. The accused denied it and it was his word against the social worker's since there were no witnesses to the threat. Faida probes into the defendant's reaction when he learned that he would not be released:

The prosecutor's voice is soft, almost caring. She asks: "So how do you react, then?" Accused: "I get angry, disappointed." Prosecutor: "How do you react when you feel that way?" The accused answers that he didn't say or do anything at all. He neither raised his voice nor screamed at the social worker. The prosecutor props her cheek against her hand and says with a kind, interested voice: "You heard the victim [social worker], she says that you're lying, so what did you say?" Accused: "Maybe I said 'you bum'?" Prosecutor: "Maybe? Is 'you bum' a word you use often?" Accused: "No." He is getting upset, raising his voice now, and his words come out harder. The prosecutor continues to be nice, but is relentless in her questioning. She looks straight at the accused.... "Well now," says the prosecutor, "could it nonetheless be, if 
you don't remember it quite so clearly yourself, that maybe what you said was 'I'll kill you, you fucking whore!"' (Observation, threatening of a public servant, Prosecutor Faida, 40+)

Although her voice remained kind throughout the examination, afterward Prosecutor Faida said that she was "professionally" irritated by the young man's attitude. She could have "tightened the screws" on him just a little bit more, to provoke an anger outburst, but "there was no intrinsic value to that, as the judges surely understood anyway how angry he can get." Choosing not to push him as far as she could, Faida demonstrated an empathetic approach, remaining respectful toward the defendant's limits, contrasting with Katla's strategy earlier. Faida managed to highlight the accused's (aggressive) character by remaining calm. She also made him admit that he did say something to the social worker. To demonstrate how unlikely it was that he had said "You bum!," her kind persona suddenly shifted to sternly repeating the threat he stood accused of ("I'll kill you"). This way, her words appeared to echo the accused.

For this poker-face strategy to work, Faida had to pay close attention to the accused's emerging anger, making the most of it without losing control of the situation (cf. Brannigan and Lynch 1987; Leiterdorf-Shkedy and Gal 2019). She could not have done this if part of her was focused on managing the irritation she recalled feeling afterward. Talking about irritation as "professional" reveals habituated professional emotion management in the background, distancing the feeling.

Habituation of relaxed emotional presence crucially enhances prosecutors' ability to attain the multiple goals they pursue in court. When the accused keeps denying the charges in spite of the evidence, the purpose of the examinations is not only, or even mainly, to obtain answers but to convey significant information to the court (Tait 2001). To this end, senior prosecutors may fake naïveté, slow-mindedness, or bad hearing. In the excerpt below, three men were accused of blackmailing and Prosecutor Bror $(65+)$ is examining one of them (Defendant 3):

Prosecutor [in pondering tone, speaking slowly]: "What strikes me as hard to understand — and I might be a bit naïve-but you travel by car, after midnight, all three of you together, to visit someone in particular, and you don't know what the trip is about?" ... Bror continues with a puzzled tone: "You've heard both Defendant 1 and Defendant 2 tell that you had a gun with youso is that information then incorrect?" Defendant 3: "Yes, it's incorrect." (Observation, blackmail, Prosecutor Bror, 65+)

Prosecutor Bror in this excerpt appears curious and puzzled, advancing the examination slowly, while reminding both the court and the defendant of the facts of the case. The strategy quietly positions Defendant 3 as a liar when he keeps denying. Bror's deliberate strategy contrasts with the performance of Magnus (discussed above), whose slow questioning signaled his lack of confidence. Bror's slowness manifests habituated confidence and a "feel for the game" (Scheer 2012), and embodied familiarity with the procedure and how to use its boundaries, including the ability to assess the patience of the presiding judge. 
We met Prosecutor Bror in a previous quote where he spoke of the anxiety of going to court. Therefore, we know that in spite of all his working years and appearing entirely confident and relaxed, he may experience unease. Not even experienced prosecutors control every aspect of their performance and procedure, because trials are collectively constructed and contingent. Relaxed emotional presence is the tool by which experienced prosecutors handle this uncertainty.

Later on in the examination, Bror asked the accused about a document that was a key piece of evidence in the case. The defendant claimed that he just happened to stumble upon the document but the prosecutor then reminded him that during the preliminary investigation he stated to the police that the document was given to him personally. At this point the defense lawyer interfered:

Defense lawyer interrupts Bror's examination with a provoking tone: "The prosecutor should read all the interrogation protocols then, because my client has given several different statements." Without looking up the prosecutor replies immediately, with a stern but low voice: "That is the defense lawyer's job to do." The defense lawyer protests, but the prosecutor pays no attention to him, continuing with the examination. (Observation, blackmail, Prosecutor Bror, 65+)

Prosecutors' slowness, or any sign of inconsistency in the presentation of the case, offers opportunity for the defense. A new prosecutor can be a sitting duck for a rude defense lawyer, but an experienced prosecutor like Bror is unperturbed. Demonstrating how relaxed emotional presence allows for flexible adaptation, Bror turns the defense lawyer's attempt to throw him off balance into a subtle counter-critique of the defense lawyer's (in)competence.

In this last section we have seen how backgrounded anxiety and habituation of confident and objective performance allow prosecutors to respond to challenges with relaxed emotional presence. They engage in interactive and improvised strategic emotion management and they surface act poker faces. Importantly, the strategic emotions and emotional displays adopted with the aim to control examinations may involve bending the feeling rules discussed in previous sections. Prosecutors breach the feeling rule of displaying confidence when they intentionally lower their status by appearing confused or slow in understanding. They breach the feeling rule of performing the objective party when they do not maintain neutrality in the same way for every examination, instead adapting the examination strategy to the person examined. The space to do this requires a judge that is sensitive and respectful of the prosecutor's work. The judge's trust may in turn be a result of the prosecutor's confident and relaxed performance, signaling experience and professional status (cf. Milner Davis and Roach Anleu 2018).

\section{CONCLUDING DISCUSSION}

This article has examined the habituation of emotion management of Swedish prosecutors, focusing on their performance in court. Prosecutors' professional emotional 
profile manifests the qualities of independence, certainty, and objectivity (Bergman Blix and Wettergren 2018). In court, these qualities follow from compliance with the feeling rules of confidence and mastering anxiety associated with an independent performance; the feeling rules of emotional distance and a balanced display associated with performing the objective party; and the playful improvisation of strategies and feeling rules associated with relaxed emotional presence. Our analysis presents these three key dimensions of habituation of feeling rules, suggesting that they are analytically ordered (the third presumes the second and the first) but empirically overlapping. Contrasting new with experienced prosecutors, we demonstrate the difference between conscious emotion management in the foreground and habituated emotion management in the background, and how the latter provides leeway to strategically use and play with the feeling rules. The routine of respecting the feeling rules and the gradual backgrounding of the related emotion management leads to habituation. The feeling rules settle in their embodied display. As suggested in the analysis, the habituation of the feeling rules of one dimension does not mean that the anxiety associated with the uncertainty of the development of a case in court, or with failure to perform the objective party, ceases to exist. It means that the prosecutors can increasingly trust their own capacity to manage uncertainty in the background, allowing an undisturbed focus on the situation at hand.

Previous research has linked routinization of emotion management to standardized practice and emotional distance (Leidner 1993). Our results show that in prosecutorial work, demanding continuous adaptation to unexpected situations, habituation of emotion management instead propels emotional presence (see Bergman Blix 2015b). Professional emotion management needs to become backgrounded for prosecutors to be able to employ strategic emotion management in examinations. When the feeling rules of professional performance are habituated, prosecutors can (a) be more present in the here and now of the court hearing and (b) allow themselves to bend the rules. Both these outcomes relate to the fact that habituated confidence admits instances of uncertainty without threatening the stable professional self. For the novice, uncertainty threatens a professional self that is still under construction and unstable.

In terms of surface and deep acting, it is noteworthy that surface acting confidence by the technique of elaborate insensitivity in the first dimension, where anxiety has to be consciously managed, changes into surface acting uncertainty as a strategic poker face in the dimension of relaxed emotional presence. In the latter dimension, confidence is the result of deep acting, moving anxiety to the background. It is thus the deep-acted confidence that allows for a playful attitude. The confident prosecutor can disregard the feeling rules of confidence and mastering anxiety, and instead present uncertainty and confusion to reach strategic (examination) goals.

Consequently, while previous research has shown high-status legal professionals like judges to deviate from the court's feeling rules by employing for strategic purposes humor (Milner Davis and Roach Anleu 2018) or anger and rudeness (Mack and Roach Anleu 2010; Scarduzio 2011), we found that prosecutors may use displays of low-status emotions. Along with previous research about prosecutors' use of caring emotions and sympathy in court examinations (Brannigan and Lynch 1987; Leiterdorf-Shkedy and Gal 2019), we suggest that these findings tie in with our concept of bounded 
independence (Bergman Blix and Wettergren 2018). Prosecutors are spiders in a web of complex relations to other legal professionals, other professional groups (e.g., police, forensics), and laypeople (defendants, victims, witnesses), on whom they depend to do their work. Emotion management to bolster these relations sometimes requires that prosecutors engage in "emotional micro-politics" (Clark 1990), lowering their own status by offering low-status emotions as gifts of humility to encourage others' confidence and willingness to collaborate (Bergman Blix and Wettergren 2018, 2019). An example of this strategy was seen when Prosecutor Faida lured the defendant to admit that he did say something to the social worker.

The important emotion management skills of prosecution in court do not belong to an organizationally acknowledged emotional reflexivity. The emotive-cognitive judicial frame, with its overarching feeling rule that being professional equals being unemotional, silences this work. Therefore, the knowledge pertaining to emotion management is tacitly communicated and acquired through trial and error, particularly manifested in court where prosecutors are on their own.

However, we have also seen how a strong team spirit of the prosecution office, constituted by intra-professional feeling rules of generosity and mutual sympathy, supports the individual. Such team scaffolding is necessary for prosecutors to perform well in spite of demanding and stressful work conditions. Supplementing previous research showing that "reciprocal emotion management" is mainly developed by subordinates (Lively 2000; Francis 2006), our analysis demonstrates that high-status groups like prosecutors may also depend on intra-professional generosity to manage frontstage emotion management. This suggests that the development of reciprocal emotion management is not linked to subordination per se, but rather explained by the outside pressure on specific groups of employees, within and/or outside the work organization.

Given that prosecutors in adversarial Western legal systems share the ideal of judicial dispassion and lack of emotion training, we speculate that studies on prosecutors in those systems will display a process of professional emotional habituation (Wettergren and Bergman Blix 2021). Moreover, our main findings may be theoretically transferable (Halkier 2011) to other professions relying on a rationality paradigm in the context of displaying independence and confidence, for instance the medical professions. Further empirical studies are needed to verify these assumptions.

From a practice perspective, our study provides a productive backdrop for the implementation of professional emotion management in legal training. In Sweden, trial games are common in law schools but they focus on legal matters, not performance. One way to reduce anxiety, and to avoid the side effect of surface acting confidence by a confrontational attitude toward defendants, could be to include professional and strategic emotion management in these games. Such training would encourage articulate reflection on the feeling rules of court performance and a constructive management of foreground emotions of uncertainty, anxiety, anticipated shame, and frustration, related to inexperienced court performance. Training could also highlight the fact that even experienced prosecutors (like Bror) continue to work with these feelings throughout professional life (cf. Goodrum and Stafford 2003); relaxed emotional presence incorporates and combines both emotional sensitivity and insensitivity. 


\section{REFERENCES}

Alvesson, Mats, and Kaj Sköldberg. Reflexive Methodology: New Vistas for Qualitative Research. London: Sage, 2009.

Austin, Debra, and Rob Durr. "Emotion Regulation for Lawyers: A Mind Is a Challenging Thing to Tame: Psychology of Persuasion Symposium." Wyoming Law Review 16, no. 2 (2016): 387-414.

Bandes, Susan A. "Loyalty to One's Convictions: The Prosecutor and Tunnel Vision." Howard Law Journal 49, no. 2 (2006): 475-94.

Bandes, Susan A, and Jeremy A. Blumenthal. "Emotion and the Law." Annual Review of Law and Social Science 8 (2012): 161-81.

Barbalet, Jack. Emotion, Social Theory, and Social Structure-A Macrosociological Approach. Cambridge: Cambridge University Press, 1998.

. "Emotions beyond Regulation: Backgrounded Emotions in Science and Trust." Emotion Review 3, no. 1 (2011): 36-43.

Bergman Blix, Stina. "Emotional Insights in the Field." In Methods of Exploring Emotions, edited by Helena Flam and Jochen Kleres, 125-33. London: Routledge, 2015a.

. "Professional Emotion Management as a Rehearsal Process." Professions and Professionalism 5, no. 2 (2015b): 1-15.

—. "Making Independent Decisions Together: Rational Emotions in Legal Adjudication." Symbolic Interaction (2021). https://doi.org/10.1002/symb.549.

Bergman Blix, Stina, and Asa Wettergren. "The Emotional Labour of Gaining and Maintaining Access to the Field." Qualitative Research 15, no. 6 (2015): 688-704.

. "A Sociological Perspective on Emotions in the Judiciary." Emotion Review 8, no. 1 (2016): 32-37.

—. Professional Emotions in Court: A Sociological Perspective. London: Routledge, 2018.

. "The Emotional Interaction of Judicial Objectivity." Oñati Socio-Legal Series 9, no. 5 (2019): $726-46$.

Brannigan, Augustine, and Michael Lynch. "Credibility as an Interactional Accomplishment." Journal of Contemporary Ethnography 16, no. 2 (1987): 115-46.

Burkitt, Ian. "Emotional Reflexivity: Feeling, Emotion and Imagination in Reflexive Dialogues." Sociology 46, no. 3 (2012): 458-72.

Clark, Candace. "Emotions and Micropolitics in Everyday Life: Some Patterns and Paradoxes of 'Place'." In Research Agendas in the Sociology of Emotions, edited by Theodore D. Kemper, 305-34. New York: State University of New York Press, 1990.

—. Misery and Company: Sympathy in Everyday Life. Chicago: University of Chicago Press, 1997.

Collins, Randall. "Theoretical Continuities in Goffman's Work." In Erving Goffman-Exploring the Interaction Order, edited by Paul Drew and Anthony Wootton, 41-63. Cambridge: Polity Press, 1988.

—. Interaction Ritual Chains. Princeton, NJ: Princeton University Press, 2004.

Czarniawska, Barbara. "Skuggning i fältarbete (Shadowing in fieldwork)." In Handbok $i$ kvalitativa metoder, edited by Göran Ahrne G and P. Svensson, 104-17. Malmö: Liber, 2011.

Damasio, Antonio R. The Feeling of What Happens: Body, Emotion and the Making of Consciousness. London: Vintage, 2000.

Elias, Norbert, and John L. Scotson. The Established and the Outsiders. London: SAGE, 1994.

Feldman Barrett, Lisa. How Emotions Are Made: The Secret Life of the Brain. Boston: Houghton Mifflin Harcourt, 2017.

Felkenes, George T. "The Prosecutor: A Look at Reality." Southwestern University Law Review 7, no. 1 (1975): 98-123.

Flam, Helena. "Emotion's Map: A Research Agenda." In Emotions and Social Movements, edited by Helena Flam and Deborah King, 19-40. London: Routledge, 2005.

Flower, Lisa. "The (Un)emotional Law Student." International Journal of Work Organisation and Emotion 6, no. 3 (2014): 295-309. 
"Doing Loyalty: Defense Lawyers' Subtle Dramas in the Courtroom." Journal of Contemporary Ethnography 47, no. 2 (2018): 226-54.

- Interactional Justice. The Role of Emotions in the Performance of Loyalty. London: Routledge, 2020

Francis, Andrew. "I'm Not One of Those Women's Libber Type People but ... ': Gender, Class and Professional Power within the Third Branch of the English Legal Profession." Social $\mathcal{E}$ Legal Studies 15, no. 4 (2006): 475-93.

Goffman, Erving. The Presentation of Self in Everyday Life. New York: Doubleday, 1959.

- Encounters: Two Studies in the Sociology of Interaction. Indianapolis, IN: The Bobbs-Merrill Company, Inc., 1961.

—. Frame Analysis: An Essay on the Organization of Experience. Boston: Northeastern University Press, 1974.

Goodrum, Sarah. 'Bridging the Gap Between Prosecutors' Cases and Victims' Biographies in the Criminal Justice System through Shared Emotions." Law and Social Inquiry 38, no. 2 (2013): 257-87.

Goodrum, Sarah, and Mark C. Stafford. "The Management of Emotions in the Criminal Justice System.” Sociological Focus 36, no. 3 (2003): 179-96.

Halkier, Bente. "Methodological Practicalities in Analytical Generalization." Qualitative Inquiry 17, no. 9 (2011): 787-97.

Harris, Lloyd C. "The Emotional Labour of Barrister: An Exploration of Emotional Labour by Status Professionals." Journal of Management Studies 39, no. 4 (2002): 553-84.

Henderson, Lynn N. "Legality and Empathy." Michigan Law Review 85, no. 7 (1987): 1574-1655.

Hochschild, Arlie R. The Managed Heart: Commercialization of Human Feeling. Los Angeles: University of California Press, 1983.

—. "Ideology and Emotion Management: A Perspective and Path for Future Research." In Research Agendas in the Sociology of Emotions, edited by Theodore D. Kemper, 117-42. New York: State University of New York Press, 1990.

Jacobsson, Katarina. "'We Can't Just Do It Any Which Way': Objectivity Work among Swedish Prosecutors." Qualitative Sociology Review IV, no. 1 (2008): 46-68.

Kemper, Theodore D. Status, Power and Ritual Interaction-A Relational Reading of Durkheim, Goffman and Collins. Farnham, Surrey, UK: Ashgate, 2011.

Lange, Bettina. "The Emotional Dimension in Legal Regulation." Journal of Law and Society 29, no. 1 (2002): 197-225.

Leidner, Robin. Fast Food Fast Talk - Service Work and the Routinization of Everyday Life. Berkeley: University of California Press, 1993.

Leiterdorf-Shkedy, Shira, and Gal, Tali. "The Sensitive Prosecutor: Emotional Experiences of Prosecutors in Managing Criminal Proceedings." International Journal of Law and Psychiatry 63 (2019): 8-17.

Lively, Kathryn J. "Reciprocal Emotion Management: Working Together to Maintain Stratification in Private Law Firms." Work and Occupations 27, no. 1 (2000): 32-63.

_. "Client Contact and Emotional Labor." Work and Occupations 29, no. 2 (2002): 198-225.

Mack, Kathy, and Sharyn Roach Anleu. "Performing Impartiality: Judicial Demeanor and Legitimacy." Law and Social Inquiry 35, no. 1 (2010): 137-73.

Maroney, Terry A. "Emotional Regulation and Judicial Behavior." California Law Review 99, no. 6 (2011a): 1481-1552.

. "The Persistent Cultural Script of Judicial Dispassion." California Law Review 99, no. 2 (2011b): 629-81.

Maroney, Terry A., and James J. Gross. "The Ideal of the Dispassionate Judge: An Emotion Regulation Perspective." Emotion Review 6, no. 2 (2014): 142-51.

McGeer, Victoria. "The Art of Good Hope." The Annals of the American Academy 592 (2004): 100-27.

Milner Davis, Jessica, and Sharyn Roach Anleu. "Judges, Judging and Humour." London: Palgrave Macmillan, 2018.

Moorhead, Richard. "The Passive Arbiter: Litigants in Person and the Challenge to Neutrality." Social E Legal Studies 16, no. 3 (2007): 405-24. 
Morton, Adam. "Epistemic Emotions." In The Oxford Handbook of Philosphy of Emotion, edited by Peter Goldie, 385-99. Oxford: Oxford University Press, 2010.

$\mathrm{Na}$, Chongmin, Tae Choo, and Jeffrey A. Klingfuss. "The Causes and Consequences of Job-Related Stress among Prosecutors." American Journal of Criminal Justice 43, no. 2 (2018): 329-53.

Pierce, Jennifer L. "Emotional Labor among Paralegals." The ANNALS of the American Academy of Political and Social Science 561, no. 1 (1999): 127-42.

Roach Anleu, Sharyn, and Kathy Mack. "Magistrates' Everyday Work and Emotional Labour." Journal of Law and Society 32, no. 4 (2005): 590-614.

-. Judging and Emotion: A Socio-Legal Analysis. Abingdon, Oxon: Routledge, 2021.

Rogers, Linda J., and Edna Erez E. "The Contextuality of Objectivity in Sentencing among Legal Professionals in South Australia." International Journal of the Sociology of Law 27, no. 3 (1999): 267-86.

Rosenwein, Barbara H. "Problems and Methods in the History of Emotions." Passions in Context 1 (2010): 1-32.

Scarduzio, Jennifer A. "Maintaining Order through Deviance? The Emotional Deviance, Power, and Professional Work of Municipal Court Judges." Management Communication Quarterly 25, no. 2 (2011): 283-310.

Scheer, Monique. "Are Emotions a Kind of Practice (and Is That What Makes Them Have a History)? A Bourdieuian Approach to Understanding Emotions." History and Theory 51, no. 2 (2012): 193-220.

Scheff, Thomas J. Microsociology: Discourse, Emotion, and Social Structure. Chicago: The University of Chicago Press, 1990.

. "Shame and Conformity: The Deference Emotion System." In Theorizing Emotions: Sociological Explorations and Applications, edited by Debra Hopkins, Jochen Kleres, and Helena Flam, 221-44. Frankfurt/Main: Campus, 2009.

Seymore, Diane, and Peter Sandiford. "Learning Emotion Rules in Service Organizations: Socialization and Training in the UK Public-House Sector." Work, Employment and Society 19, no. 3 (2005): 547-64.

Smith, Abbe. "Can You Be a Good Person and a Good Prosecutor?" Georgetown Journal of Legal Ethics 14, no. 2 (2000): 355-400.

_. "Are Prosecutors Born or Made?" Georgetown Journal of Legal Ethics 25, no. 4 (2012): 943-60.

Tait, David. "Popular Sovereignty and the Justice Process: Towards a Comparative Methodology for Observing Courtroom Rituals." Contemporary Justice Review 4, no. 2 (2001): 201-18.

Thoits, Peggy A. "The Sociology of Emotions." Annual Review of Sociology 15, no. 1 (1989): 317-42.

Weber, Max. "Bureaucracy." In From Max Weber: Essays in Sociology, edited by H. H. Gerth and C. Wright Mills, 196-244. New York: Routledge, 1998.

Wettergren, Åsa. "How Do We Know What They Feel?" In Methods of Exploring Emotions, edited by Helena Flam and Jochem Kleres, 115-24. London: Routledge, 2015.

—. "Emotive-Cognitive Rationality, Background Emotions and Emotion Work." In Emotions in Late Modernity, edited by Roger Patulny et al., 27-40. London: Routledge, 2019.

Wettergren, Åsa, and Stina Bergman Blix. "Empathy and Objectivity in the Legal Process: The Case of Swedish Prosecutors." Journal of Scandinavian Studies in Criminology and Crime Prevention 17, no. 1 (2016): 19-35.

. "Comparing Culturally Embedded Frames of Judicial Dispassion." In Research Handbook on Law and Emotion, edited by Susan A. Bandes et al., 146-63. Northampton, MA: Edward Elgar Publishing, 2021.

Zila, Josef. "The Prosecution Service Function within the Swedish Criminal Justice System." In Coping with Overloaded Criminal Justice Systems, edited by Jörg-Martin Jehle and Marianne Wade, 285-311. Berlin: Springer, 2006. 